\title{
Nickel - Tungsten CCAs Electro-deposition Morphology Investigation
}

\author{
Jalil Ebrahimi Baran*, Saeid Rastgari \\ Faculty of Materials and Metallurgy, Iran University of Science and Technology, Tehran, Iran \\ Email address: \\ j.ebrahimibaran@gmail.com (J. E. Baran) \\ ${ }^{*}$ Corresponding author \\ To cite this article: \\ Jalil Ebrahimi Baran, Saeid Rastgari. Nickel - Tungsten CCAs Electro-deposition Morphology Investigation. American Journal of \\ Mechanical and Materials Engineering. Vol. 5, No. 3, 2021, pp. 44-54. doi: 10.11648/j.ajmme.20210503.12
}

Received: May 15, 2021; Accepted: July 2, 2021; Published: November 12, 2021

\begin{abstract}
Complex concentrated alloys (CCAs), are based on mixed elements to stabilized solid solution (S.S). properties come from S.S micro-structures present special mechanical and tribological properties. Producing process of these excellent alloys cost huge amount of money and time that would be economiced if could be quantified to surface instead of bulk counterpart, due to environment and condition of industrial usages and applications. Nickel-tungsten alloys electro-deposited show Distinct properties in coating layer as the same as CCAs. Refractory elements such as; W, Ti, Mo, Hf, Nb, Zr, Ta, and V, offer high temperatures and hardness properties which made their valuable in high-tech applications. Purveying coating from an aqueous bath of $0.1 \mathrm{M} \mathrm{NiSO}_{4}, \mathrm{M} 0.5 \mathrm{Na}_{2} \mathrm{WO}_{4}$ and $\mathrm{M} 0.4 \mathrm{Na}_{3} \mathrm{Cit}$ at $\mathrm{pH}=8$ and $70^{\circ} \mathrm{C}$ in a cathode rotation bath (for agitation) at a speed of 200 to $750 \mathrm{rpm}$, and direct current density $0.05-1.2 \mathrm{~A} / \mathrm{cm}^{2}$ has been investigated in presence work. Tungsten has the essential role, as refractory element, in HEAs that affects on morphology and microstructure of alloys. The amount of tungsten in plating was $45.49 \%$ by weight in direct current plating, and in $80 \%$ D.C. reach 62.8 wt $\%$ in pulse current. The percentage of tungsten in the coating is strongly affected by the $\mathrm{pH}$ of the solution, the current density and the percentage of Time on. The anamolous deposition system in direct current was transformed into an induction deposition system in a pulsed electroplating process. The coating morphology becomes coarser as the amount of tungsten of the coating grains increases. At low Time-on percentages, the coating morphology is layered, bladed and porous. As the percentage of Time-on increases, the layers become wider. Grain size and structure had affected by kind of current, wereas coarser grains observed in pulse deposition coating, flat appurtenant is even in DCEP process.
\end{abstract}

Keywords: Nickel-Tungsten Alloy Plating, Nickel-Tungsten CCAs, HEAs Coating, HEAs Amorphous Morphology, CCAs Coating Properties

\section{Introduction}

Tungsten (W) is an extremely interesting material due to its unique properties, like its thermal stability $(\mathrm{Tm}=3693$ $\mathrm{K})$, high density $\left(\rho=19.30 \mathrm{~g} / \mathrm{cm}^{3}\right)$, mechanical properties $(\mathrm{H}$ $=3.53-5.884 \mathrm{GPa} ; \mathrm{E}=407 \mathrm{GPa})$, wear resistance and electric conductivity $(5.49 \mu \Omega \mathrm{cm})$. It is used in a wide variety of applications, such as diffusion barriers in interconnects [1-9], metallization layers, X-ray masks [10] and mirrors [11-13] nuclear applications [14]. and even in green house application, used as catalysts in hydrogen reduction processes and alkaline water electrolysis with successful electro-catalytic effects and also hydrogen containers. Besides, it was expressed that deposition current density, tungsten content, and other factors affecting the morphology of coatings are important in the enhancement of catalytic efficiency [10-21].

Heat treatment improves the mechanical properties of the coating and heightens its quantities. Obviously, the hardness and thermal strength of molds are enhanced by the use of Nickel-Tungsten alloy. Moreover, due to the electro-catalytic properties and behavior of this alloy, it has high corrosion resistant applications, especially in the oil and marine industries [5-9].

Obradovic also points out, Ni - W alloys have some special characteristics such as corrosion resistance, fracture resistance, and $\mathrm{H}_{2}$ catalytic activity [10].

X-ray diffraction (XRD) study by Frant Sevich and 
Zabludivskaya demonstrated homogeneity compared to Tungsten-Nickel metal solution in the precipitated structure [11]. Theoretically and practically, Tungsten as a refectory elements in CCAs due to their role in making solid solution homogenous up to 12.5 at $\%$ and preparing unstable microcrystal phase in $\mathrm{Ni}$ matrix witch enhanced excellent behavior in industrial usages [14].

Full micro structural control towards nanocrystalline morphology is expected to further promote these properties, especially with regard to thin film applications. Similarly improved properties, as increased hardness, enhanced toughness, or superior chemical, optical and magnetic properties, Due to their novel deformation physics, as grain size reaches the nanometer range, traditional intragranular dislocation mechanisms for plasticity are suppressed and deformation becomes dominated by grain boundary processes such as grain boundary dislocation emission [22-24], grain boundary sliding $[25,26]$, and grain boundary migration [27-29].

What complicates this task is that when an alloying addition and a nanoscale grain size are present, both have potentially significant effects on properties and the two are difficult to decouple systematically because composition affects structure. For example, in the electrodeposited Ni-W alloys mentioned above, grain size is intimately tied to composition [30], and changing one of these variables tends to cause changes in the other (at least in the as-deposited state). Detailed studies that isolate the effects of grain size (Hall-Petch strengthening by fining grain size) and composition for various systems (solid solution, phase separating, etc.) are needed. These are for the most part somewhat speculative, again because they are generally unable to separate the effects of composition and grain size. The finest nanocrystalline metals (from amorphous to $\sim 10$ $\mathrm{nm}$ grain size) may only be achievable through (i) use of a low-temperature single-step production process, and (ii) careful selection of the alloy composition.

Various routes have been proposed such as severe plastic deformation, physical vapor deposition, chemical vapor deposition etc. Each of these processes have their own advantages and disadvantages (e.g. sophistication, cost). One of the simplest and economical way to synthesize nanocrystalline materials is through electro-deposition. Electro-deposition is gaining importance due to its ability to deposit refractory materials like tungsten (W), molybdenum (Mo) etc., using ferrous metals resulting in an alloy with superior properties. One of such kind of alloy is $\mathrm{Ni}-\mathrm{W}$, in which refractory metal $\mathrm{W}$ is used to deposit using a ferrous metal Ni.

Coatings had cracks and the crack density increased as the $\mathrm{W}$ percentage increased [31-33]. This was mainly due to the use of direct current (DC) that results in excessive hydrogen evolution leading to cracks in the coating. By Using additives in the bath, crack density would be decreased but its side effect, results in the presence of carbon and sulfur in the coatings, which segregate to the grain boundaries causing grain boundary Embrittlement, reduction in mechanical strength and stress corrosion cracking. To overcome this, pulse electrodeposition (PED) was employed. The major advantage of PED over DCED is that in a short period of time, high pulse can be given which polarizes the cathode and during pulse off-time reduction in concentration polarization takes place leading to concentration built up near the cathode electrolyte interface. This results in fine grained crack free deposits. However, in case of PED precise control of grain size and alloy composition that without use of additives is still difficult [34]. Mizushima et al. [35] studied the effect of complexing agent (in the bath) on the residual stress of $\mathrm{Ni}-\mathrm{W}$ alloy coatings. They found that use of pulse current (PED) reduced the magnitude of residual stress in the coating due to the removal of hydrogen during the anodic pulse.

In this work we study the structure and properties of nanocrystalline Ni-W alloys with grain sizes (below $10 \mathrm{~nm}$ ). These alloys are produced by direct current (DC) and pulse current (PED) electro-deposition, and represent a good starting point to understand the effect of morphology on complex mechanical behavior of multicomponent nanocrystalline $\mathrm{Ni}-\mathrm{W}$ alloys in the nanocrystalline and amorphous state of coating [11, 12].

\section{How to Do the Tests}

Nickel-Tungsten alloy electrical plating with fixed composition in bath (table 1 ) at $\mathrm{pH}=8$ was used in this study (Younes and Gileadi [7]).

Table 1. Bath composition used in Nickel-Tungsten alloy coating.

\begin{tabular}{lll}
\hline $\mathrm{NiSo}_{4}$ & $\mathrm{Na}_{2} \mathrm{Wo}_{4}$ & $\mathrm{Na}_{3} \mathrm{Cit}$ \\
\hline $0.1 \mathrm{M}$ & $0.5 \mathrm{M}$ & $0.4 \mathrm{M}$ \\
\hline
\end{tabular}

In the experiments, the copper wire with $8 \mathrm{~mm}$ in diameter and $5 \mathrm{~cm}$ in length was used as a cathode, stainless steel 316 $\mathrm{L}$ with a dimension of $3 \times 5 \mathrm{~cm}^{2}$ as anode, at a temperature of $70^{\circ} \mathrm{C}$, density of $0.05-0.12 \mathrm{~A} / \mathrm{cm}^{2}$. In order to cause turbulence, cathode rotation speed was 200-750 rpm.

Investigations was done using the Scanning Electron Microscope (SEM) of the Cambridge S 360 model and the Constant Current Generating Station (Galvano Static) model of the CP S 20A and the HS 2000 model and the thermostat 609 R 351 for stabilizing temperature. In order to make turbulence in solution a motor of vehicle fan was employed with a maximum rotational speed of $3000 \mathrm{rpm}$ for agitation and the wire cathode role (figure 1).

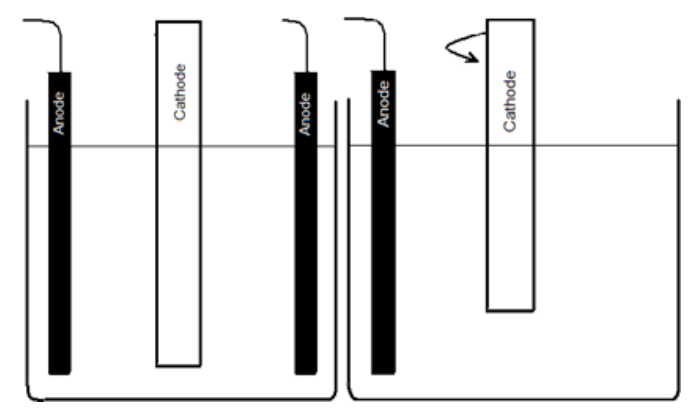

Figure 1. Schematic of Nickel-Tungsten alloy lating.(Left figure): Sheet cathode.(Right figure): Wire cathode. 


\section{Discussion and Results}

Although the equilibrium phase diagram of the $\mathrm{Ni}-\mathrm{W}$ system is speculative at room temperature, $\mathrm{W}$ is expected to dissolve in $\mathrm{Ni}$ up to $\sim 12.5$ at $\%$ (figure 2). Most of the electrodeposited coating, in fact, exceed the expected solubility limit for $\mathrm{W}$ in $\mathrm{Ni}$ (in our experiment, atleast). This disagreement with the equilibrium phase diagram suggests that these materials are probably metastable solid solutions. Since fully amorphous Ni-W alloys can be produced by electrodeposition [36, 37], it is reasonable for a nonquilibrium solid solution nanocrystalline phase to exist in this system as well.

The commonly used plating bath for $\mathrm{Ni} / \mathrm{W}$ deposition consists of a solution of $\mathrm{NiSO}_{4}, \mathrm{Na}_{2} \mathrm{WO}_{4}$, and $\mathrm{Na}_{3} \mathrm{Cit}$, in which the $\mathrm{pH}$ is adjusted with sulfuric acid and ammonium hydroxide to a value of 8.0. At this $\mathrm{pH}$ citric acid is predominantly in the form of the $\mathrm{Cit}^{3-}$ ion (figure and equation). The presence of an amorphous-nanocrystalline microstructure which exhibits enhanced hardness, metallic conductivity, and sub-nanometer root mean square (RMS) roughness. Because of non-trivial and high cost of singlecrystal metal films deposition, for accessing similar properties, creating an amorphous or amorphousnanocrystalline microstructure is on the table.

Tungsten dissolution in nickel matrix leads to expansion of nickel lattice. According to the Ni-W phase diagram (figure 2), tungsten may dissolve in nickel by 12.5 at $\%$ in equilibrium condition. regarding the abnormal compound observed, XRD and XPS results, at $2 \theta=41.8^{\circ}$ which faded by annealing at $550^{\circ} \mathrm{C}$, suggest that this compound may be associated with nonstoichiometric nickel tungsten oxide $\left(\mathrm{NiWO}_{4}\right)$ [39-41]. Sridhar et al. [41] reported the formation of $\mathrm{Ni}_{4} \mathrm{~W}$ phase (with an observed peak at $2 \theta=50.4^{\circ}$ ) with body centered tetragonal structure in alloys deposited at extremely low current densities and high temperatures. When the tungsten content reaches the critical value of 20 at $\%$, the crystalline structure is changed to amorphous state [42-44]. It may be seen that by an increase in tungsten content grains become finer and nanocrystalline structure is converted to an amorphous state. It was also reported that atomic distance, lattice parameter, and fraction of grain boundaries in nanocrystalline $\mathrm{Ni}-\mathrm{W}$ raise by enhancing in tungsten content [45-49]. Herein, Juskenas et al. [50] developed a theoretical linear equation between lattice parameter and tungsten Content content:

$$
\mathrm{X}_{W}=-7.5208+2.13429 \times \alpha_{N i-W}
$$

Where, $X_{W}$ is tungsten atomic percentage and $\alpha_{N i-W}$ is FCC lattice parameter in $\gamma$ phase.

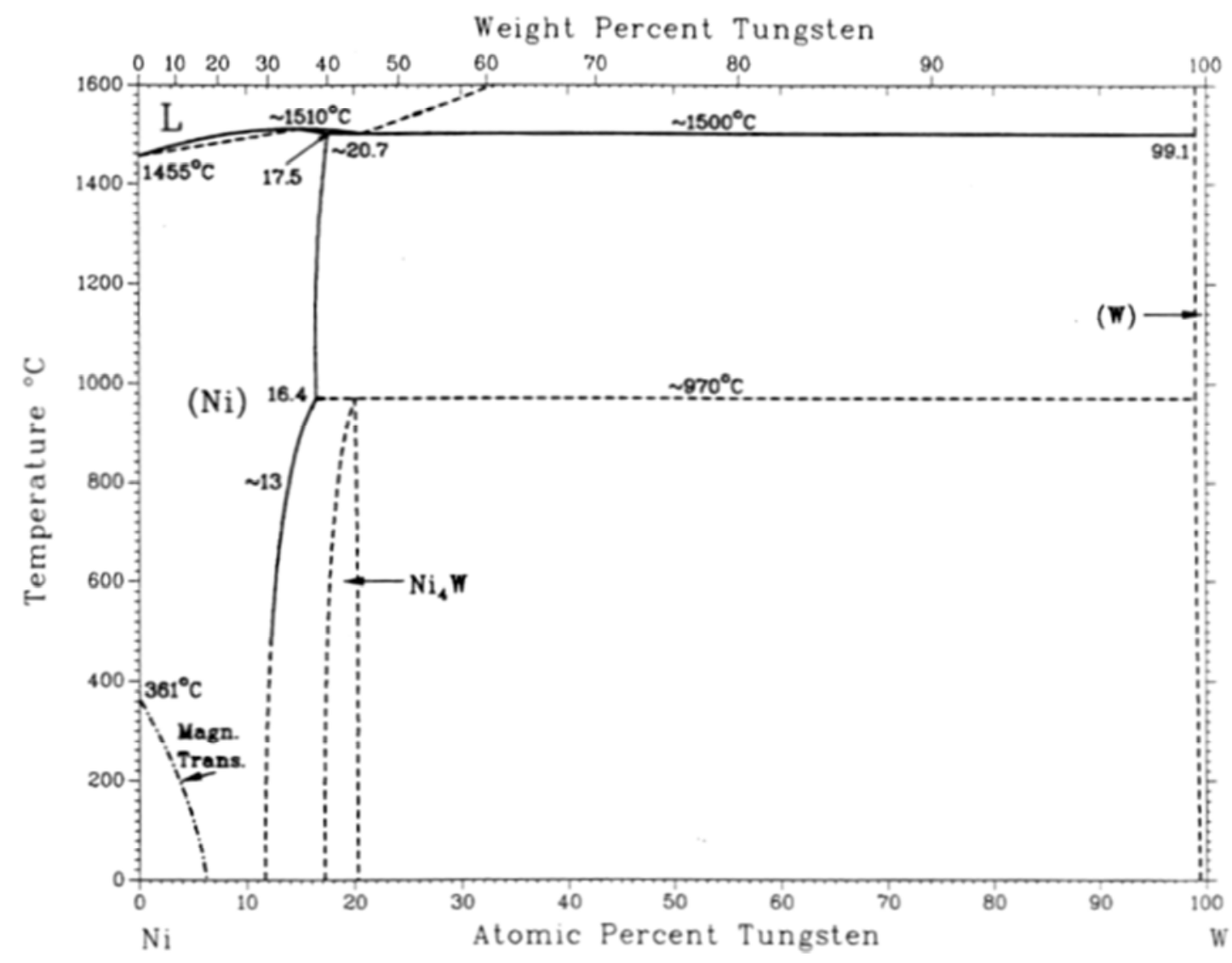

Figure 2. Ni-W phase diagram.

Considering the chemical composition based on the nickeltungsten phase diagram, the nickel alloy with 7 at \% tungsten is located in the region of tungsten solid solution in the nickel where an increase in annealing temperature and time leads to 
the formation of coarse grains. Besides, the nickel alloy with 14 at \% tungsten is located in the $(\mathrm{Ni})$ and Ni4W two-phase region where an increase in annealing temperature leads to the growth of $\mathrm{Ni} 4 \mathrm{~W}$ intermetallic precipitates in the $(\mathrm{Ni})$ matrix and consequently increase in hardness of alloys [38].

The new phase also indicates higher tungsten content in comparison to the $\mathrm{Ni}_{16} \mathrm{~W}_{3}$ phase as confirmed by the EDAX results (figure 3). This tungsten-enriched phase might be marked as NiW (6/3) phase and is called an amorphous phase in this paper.

It is assumed that electro-crystallisation of the tungstenenriched phase appeared first, and then followed the deposition of $\mathrm{Ni}_{16} \mathrm{~W}_{3}$ after the exhaustion of a certain amount of tungsten. It is suggested that each of the alloys consists of two phases: the crystalline and the amorphous phase. The crystalline phase is formed mostly from the higher than 20 at $\%$. The transition between the nanocrystalline and amorphous phases is a matter of definition. Some kind of short-rangeorder is always present even in the amorphous materials. As the average current density increases (figures 4 and 5), W content with the grain size diminishing, the deposit surface is smoothed out which is in accordance with the theory.

Figure 5 revealed that $\mathrm{Ni}-\mathrm{W}$ coatings produced at $70^{\circ} \mathrm{C}$ contained the most amount of $\mathrm{W}$ in $\mathrm{DC}$ process. Morphology of samples in different temperatures indicated that by bath temperature rising up, continuous texture of coat and lower amount of cracks with increasing $\mathrm{W}$ content were produced (figure 4). Where existence of long and depth cracks are obviously appeared in $50^{\circ} \mathrm{C}$, in $70^{\circ} \mathrm{C}$, in both views of lateral and direct, amount of crack is diminished. The formation of cracks can be mainly related to the significant hydrogen embrittlement and tensile stress formation that occurs during $\mathrm{Ni}-\mathrm{W}$ electro-deposition and effect of the residual stress of the coatings.
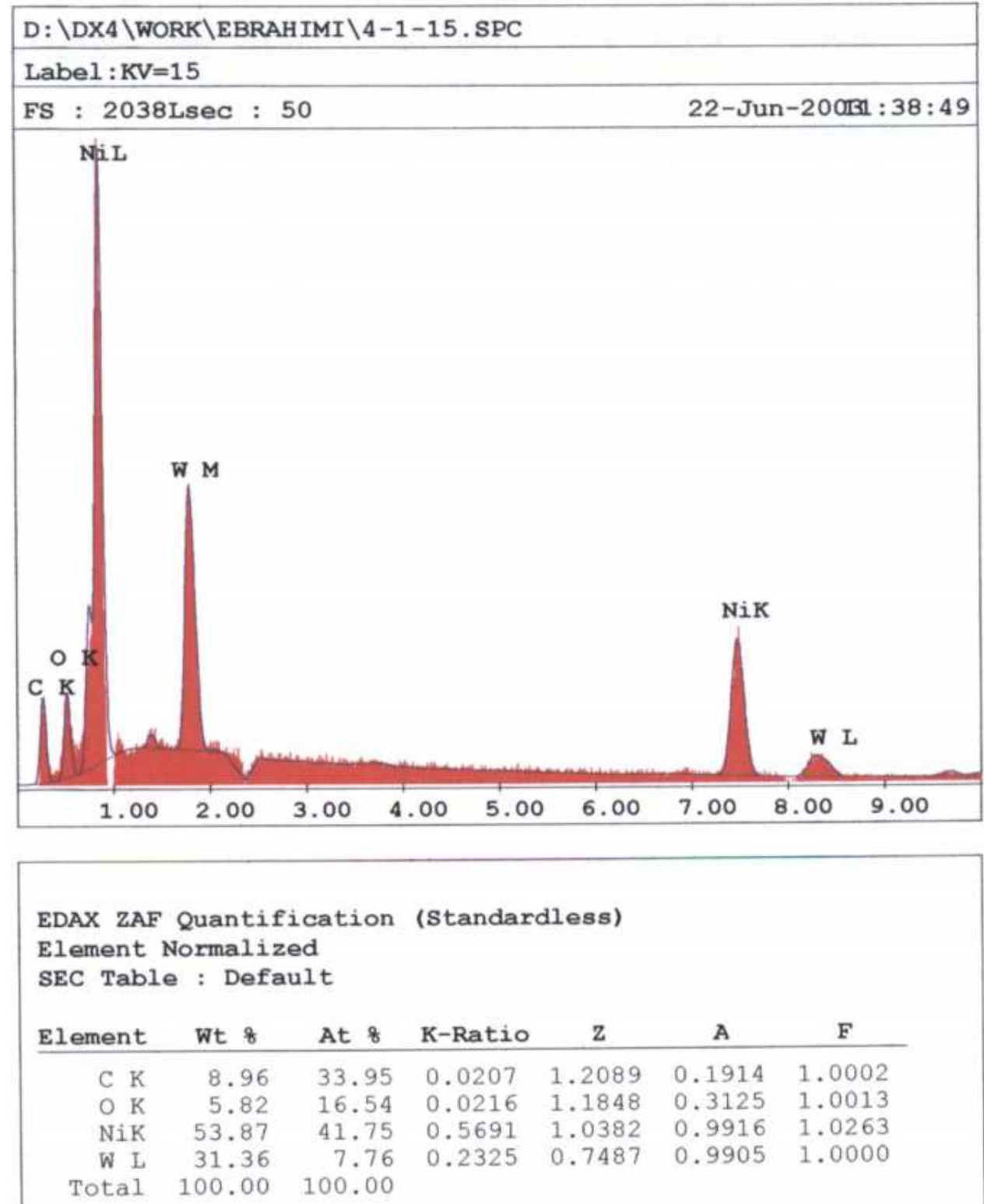

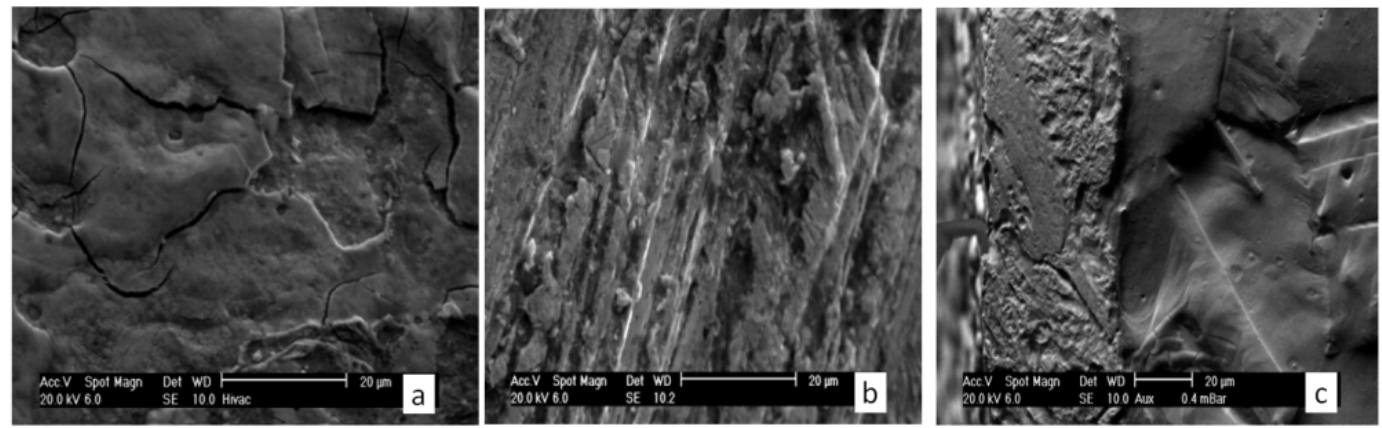

Figure 4. SEM surface morphology DCED (a); $50^{\circ} \mathrm{C}(\mathrm{b}) ; 70^{\circ} \mathrm{C}$, (c); cross section of (b).

Besides, current density affects nickel-tungsten film texture and seems to be substantially effective on surface morphology of nickel-tungsten coatings. As it is shown in figure 4 , lower current densities lead to the formation of smooth nanocrystaline coatings with compact morphology; while by an increase in current density, the $\mathrm{W}$ wt $\%$ decreased in DC, but increased in PED.

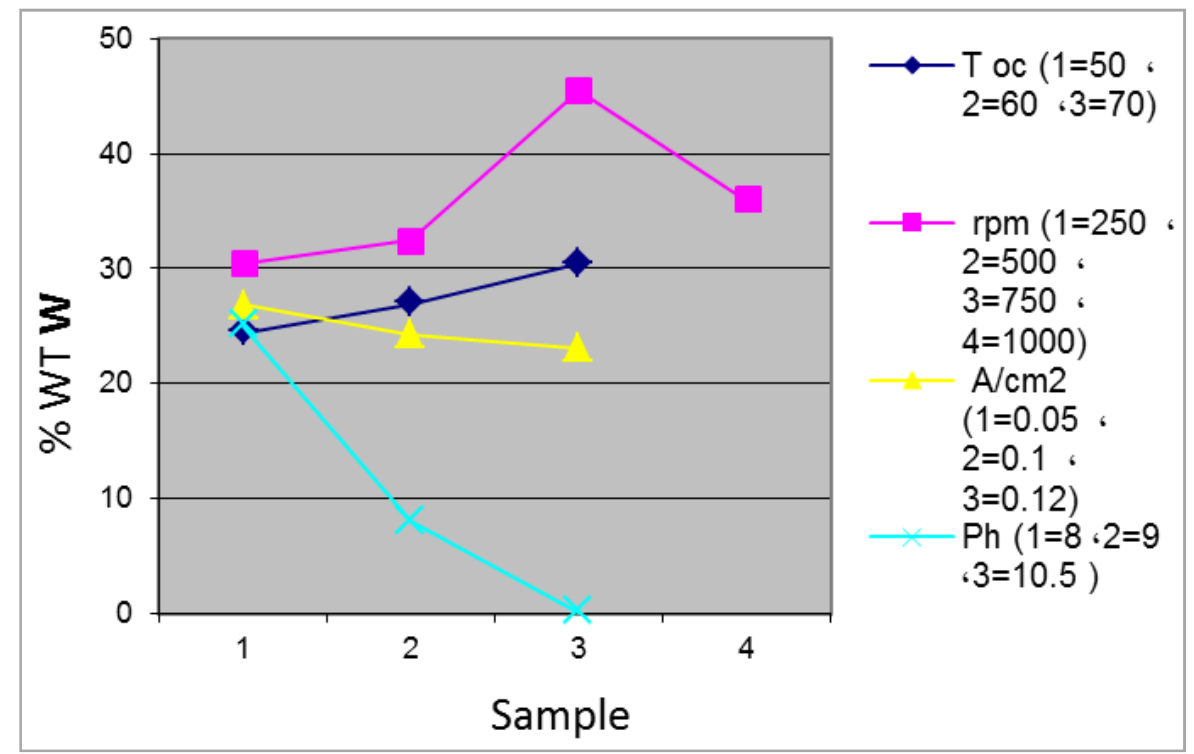

Figure 5. $W$ wt\% variations v.s D.C, Tem, rpm, Ph in ED coating.

The optimum conditions for the electrodeposition of crackfree, homogeneous nanocrystalline $\mathrm{Ni}-\mathrm{W}$ coatings were determined on the basis of the microstructure investigation results. X-ray and electron diffraction patterns of all nanocrystalline $\mathrm{Ni}-\mathrm{W}$ coatings revealed mainly the fcc phase structure of an a-Ni (W) solid solution with a lattice parameter increased along with tungsten content. Role of citrate species as an important factor to achieve the desirable morphology and structure of deposits could not be disregard. With increasing tungsten content a clear refinement of the nanocrystalline structure occurs. Such nanostructures have interesting practical applications and are very important from fundamental science point of view. Consequently, $\mathrm{Ni}-\mathrm{W}$ coating microstructure is characterized by a combination of the amorphous and nanocrystalline phases. As can be seen from the dependence shown in figure $6, \mathrm{Ni}-\mathrm{W}$ coatings produced under the presented galvanic conditions consist of about $40-45.4 \mathrm{wt} \%$ of tungsten. A slight decrease in the refractory metal content was observed with the increasing current density, which was associated with an increase in the rate of $\mathrm{Ni}-\mathrm{W}$ alloy electrodeposition at a controlled discharging process of $\mathrm{Ni}[51,52]$.

At the cathode current density of 0.05 to $0.12 \mathrm{~A} / \mathrm{cm}^{2}$. It was confirmed that, with increasing electrodeposition current density (increase in the polarization of the cathode), nanocrystalline $\mathrm{Ni}-\mathrm{W}$ alloys contain smaller amounts of tungsten, while increasing the crystallite size. As can be seen in figure 6, coatings obtained at lower current density have an average crystallite size of about $15 \mu \mathrm{m}$. A considerable increase in the current density to $0.12 \mathrm{~A} / \mathrm{cm}^{2}$ caused a two fold increase in the crystallite size of the $\mathrm{Ni} W$ coating (while decreasing the tungsten content in the alloy of 45.4$24.3 \mathrm{wt} \%$ ). The observed effect is consistent with the following literature reports [46].

Regarding incorporation of nanoparticles within Ni-W alloy matrix, increasing current density up to an optimum level consistently leads to increase in nanoparticles content within the coating. However, a further increase in current density shows an inverse trend. An increase in cathodic current density up to $0.12 \mathrm{~A} / \mathrm{cm}^{2}$, the embedded diamond nanoparticles content were increased within $\mathrm{Ni}-\mathrm{W}$ coating. 

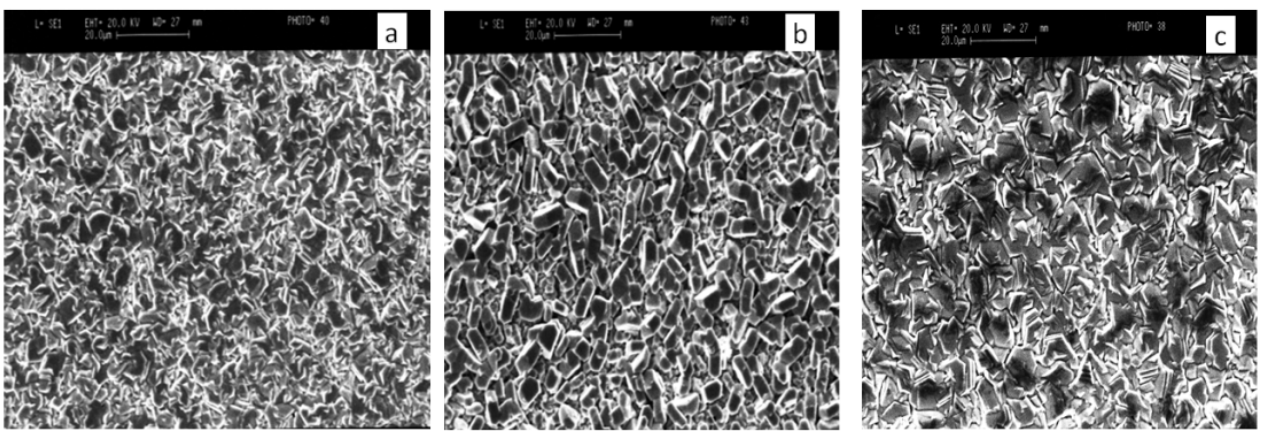

Figure 6. SEM surface microstructure DCED (a); $0.05 \mathrm{~A} / \mathrm{cm} 2$, (b); $0.1 \mathrm{~A} / \mathrm{cm} 2$, (c); $0.12 \mathrm{~A} / \mathrm{cm} 2$.

By increasing current density, microstructures of coating have changed from small hexagonal grains to larger hexagonal and finally formed to pyramid.

The use of additives in the plating bath resulted in the formation of quiaxial/quasifibrous, nanocrystalline $\mathrm{Ni}-\mathrm{W}$ grains of an average size of about $10 \mu \mathrm{m}$ (figure 6). Glycolic acid as complexing agent is beneficial for forming $\mathrm{Ni}-\mathrm{W}$ coatings with finer grains and smoother surface.

It can be seen from (Figures 6, 7, and 8) that the coatings obtained from two different systems (DC and PED), Crystalline growth along planes of (llll 111$),\left(\begin{array}{lll}2 & 0 & 0\end{array}\right),\left(\begin{array}{lll}2 & 2 & 0\end{array}\right)$, and $\left(\begin{array}{lll}3 & 1 & 1\end{array}\right)$ orientation owing to the lower strain in that direction and lower angles with respect to pure fcc $\mathrm{Ni}$ was observed in figure 8 , which can be attributed to the incorporation of tungsten atoms into the nickel lattice. It can be seen also that nanocrystals tend to be broader and shift to larger angles with increasing theW content in the coatings specially in PED samples.

possibly a coexistence of a non-equilibrium solid solution with a metastable solid solution exists, even exceeding the solubility limits of $\mathrm{W}$ in the $\mathrm{Ni}-\mathrm{W}$ alloy. Therefore, although the studied Ni-W layers in this work have $\mathrm{W}$ content of lower amount of 20 at.- $\%$ in DC samples, it is not surprising that they are constituted of a solid solution of $\mathrm{W}$ with $\mathrm{Ni}$ matrix. The existence of a small fraction of amorphous Ni-W in DC films cannot be ruled out. Actually, the lower hardness of $\mathrm{DC} \mathrm{Ni}-\mathrm{W}$ coatings might be ascribed to the formation of this fraction of amorphous phase during electrodeposition and the transition from the conventional Hall-Petch relation to breakdown behavior (inverse Hall-Petch) [54, 55].

The typical SEM surface morphology of the Ni-W coating obtained in DC and PED. A tendency to change the coating surface morphology to a globular one (cauliflower-like structure) with increasing cathodic current density was observed. SEM Ni-W observations showed that the coating obtained in both current was characterized by a nanocrystalline, equiaxed microstructure of Ni-W solid solution (figures 7 and 8). An appropriately selected concentration of the plating bath allows $\mathrm{Ni}-\mathrm{W}$ coatings of amorphousor nanocrystalline microstructure of varying composition to be obtained. Simultaneously, by changing the operating parameters of the electrolysis process (bath factors and DC or PED parameters table 2), one can control the chemical composition, microstructure and crystallite size of $\mathrm{Ni}-\mathrm{W}$ coatings.

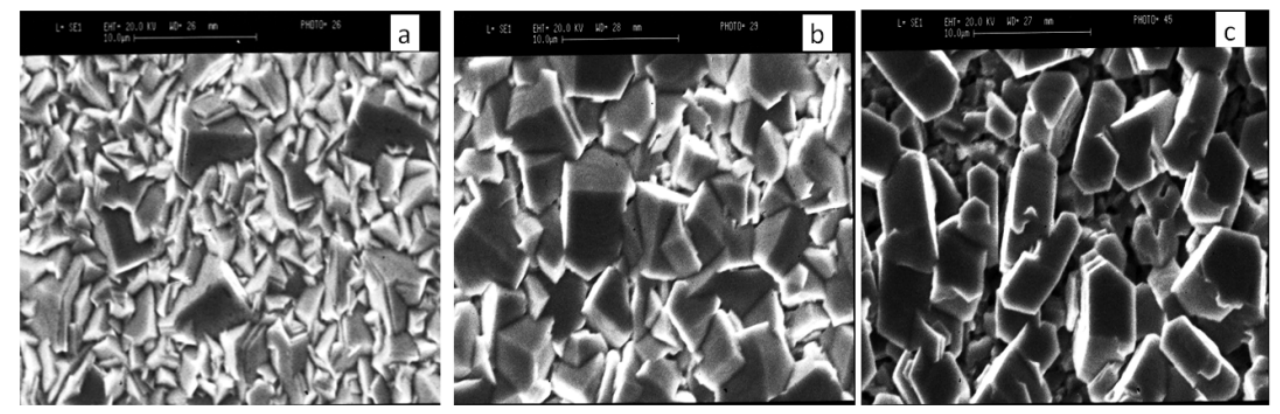

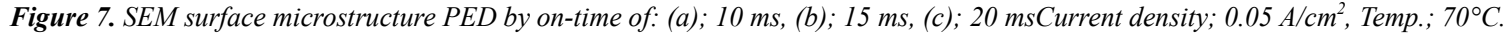
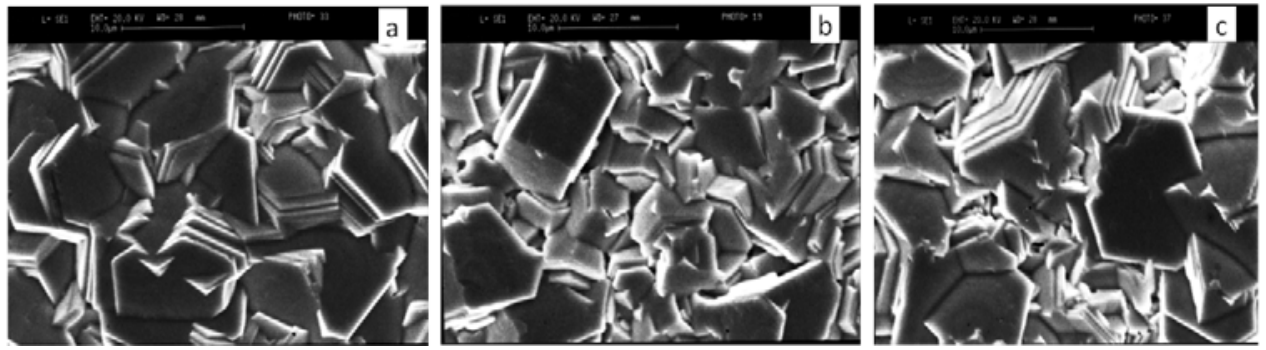

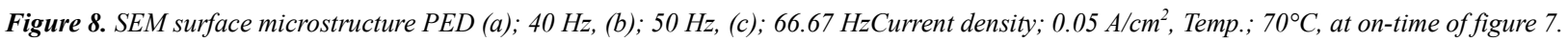


The presence of nodules having a cauliflower-like structure of various sizes and arrangments are observed in figures 9 and 11 illustrate that the number of nodules and their size decreased with increasing the current density. This behavior can be associated with the decrease of the tungsten content in the coating. According to Ribic-Zelenovic et al. [53], increasing current density leads into raising hydrogen evolution rate, which indirectly affects the characteristics of the obtained coating. The evolution of hydrogen can significantly affect the alloy morphology and particle size distribution of the coatings (figure 10). It was noted that with increase in the current density the presence of micro cracks in the alloys $\mathrm{Ni}-\mathrm{W}$ increased with association of tungsten content and internal tension, thus causing an increase of micro cracks and voids $[55,56]$.

Table 2. PED parameters on Ni-W electro-deposition in preparing 7 examples.

\begin{tabular}{|c|c|c|c|c|c|c|c|}
\hline \multicolumn{8}{|l|}{ PED work summery } \\
\hline sample & 1 & 2 & 3 & 4 & 5 & 6 & 7 \\
\hline On-Time (ms) & 5 & 10 & 5 & 15 & 5 & 20 & 5 \\
\hline D.C. $\%$ D. C. $=\frac{T_{O N}}{T_{O N}+T_{O F F}}$ & 50 & 66 & 33 & 75 & 25 & 80 & 20 \\
\hline Ferq. (Hz) & 100 & 66.67 & 66.67 & 50 & 50 & 40 & 40 \\
\hline W wt $\%$ & 46.6 & 55 & 52.3 & 56.5 & 54.6 & 62.8 & 36.4 \\
\hline
\end{tabular}

This behavior can also be associated with accession in crystallite size and formation of nano-crystalline alloy with partially amorphous nature. According to Yamasaki et al. [13, 20] the structure of $\mathrm{Ni}-\mathrm{W}$ coatings are influenced by both the current density as well as the temperature of the electrolytic bath. According to Feng-jiao et al. [57, 58] ternary alloys can modify from crystalline to amorphous structure with a lower content of tungsten.

It was observed that the hardness increased with increasing tungsten content in the alloy. With decreasing grain size the micro-hardness was increased obeying the direct relation of Hall-Petch [59, 60].

Strengthening mechanism

Therewith local dislocation pinning strengthening mechanism, as traditional solid solution model of at solute atoms, considering grain boundaries as pinning points for dislocation motion in nanocrystalline materials in combine each other, are essential effective factors in excellent CCA or HEAs (Complex Concentrated Alloys or High Entropy Alloys) properties. The new strengthening term arises by and incorporating the effect of solutes on such a mechanism.

There are three ways to harden HEAs, all of them are built on the addition of appropriate elements to produce targeted microstructures. Each strategy aims to: (i) promote the formation of multi-phase HEAs, (ii) obtain a controlled nanoprecipitation in a compositionally complex solid solution for high temperature applications, and (iii) control alloy chemistry to activate induced plasticity effects under stress, mainly at room temperature.

Substantial increases in strength - while keeping reasonable ductility - could be achieved if precipitation is controlled, i.e. if the precipitates are coherent and finely dispersed in the matrix. A targeted strategy for HEAs is very similar to that developed in duplex $\gamma-\gamma^{\prime}$ superalloys and leads to the research of hardened fcc or bcc-HEAs with nanosized reinforcing phases.

$3 \mathrm{~d}$ transition metals and refractory metals as principle elements, the next generation explores a broader landscape comprising multi-phase microstructures. Our discussion surrounding $\mathrm{Ni}-\mathrm{W}$ also provides insights into other solid solution nanocrystalline systems, A variety of which we show can be accurately described using the same concept.

In DC process, by increasing $\mathrm{W}$ content, which took place in opposite direction of current density accretion, up to 45.49 $\mathrm{wt} \% \mathrm{~W}$ in $70^{\circ} \mathrm{C}$ and $0.05 \mathrm{~A} / \mathrm{cm}^{2}$, microstructure (nanocrystalline fcc with smallest average grain size to $\sim 5 \mathrm{~nm}$ ) is observed (figure 6), in the same bath condition and 0.14 $\mathrm{A} / \mathrm{cm}^{2}, \mathrm{~W}$ wt $\%$ dropped down to $23 \mathrm{wt} \%$ and nanocrystalline fcc sizes grow up around $15 \mathrm{~nm}$ in big grain and average 8$10 \mathrm{~nm}$ that are respectively represented in SEM images in Figure 7.

In PED, referring to table 2, further increasing the $\mathrm{W}$ content up to $62.8 \mathrm{wt} \% \%$ gradually, in same bath condition except pulse current as; $0.05 \mathrm{~A} / \mathrm{cm}^{2}, 40 \mathrm{~Hz}, \% 80$ D.C. TEM images (figure 7) showed increasing manor of nanocrystalline grain size up to $12 \mu \mathrm{m}$. By increasing frequency, images illustrated grain size crunching into smaller parts. PED process has indicated strange behavior; whatever D.C amount increased, nanocrystalline structures tended to hexagonal parallel plane geometry with enlarging grand's size while $\mathrm{W}$ amount is rising.

In summary, Ni-W alloys can be deposited with nanocrystalline, dual-phase nanocrystalline-amorphous, or fully amorphous, microstructures. Nanocrystalline strengthening has a dependence on grain.

At ambient temperatures the dislocation locking mechanism can be described by Fleischer's work [61] in which solute atoms are assumed to act as point defects which resist dislocation motion. Labusch's theory [62], on the other hand, considers the solute atom to exert a drag-type force on the dislocations; a stronger pinning of dislocations by the solutes then results. Therefore, a critical grain size exists where the solid solution effect predicted by both models is of equal magnitude, separating regimes of dominance for the two effects.

In our work, funding critical size of nanocrystalline solution in electro-deposition process and amorphous grain size, for getting best desired properties of CCAs in coating, would be practical and industrial attempt.

By altering the pulse parameters we got different alloy compositions and found that pulse frequency has a significant effect on alloy composition, grain size, thickness, hardness and corrosion resistance of the coatings. As is shown in figure 9 and 11, Ni-W alloy coatings had cauliflower like structure. Coatings deposited using low frequencies showed the large amount of $\mathrm{W} \% \mathrm{wt}$. while D.C had increasing manor, $\mathrm{W}$ content in the alloy increased to highest value of our examinations $(62.8 \% \mathrm{wt})$ in D.C. $=\% 80$ with micrographs 
of $\mathrm{Ni}-\mathrm{W}$ coatings represents cauliflower type morphology. Mechanism of appearing cauliflower structure seems to be followed of Volmer-Weber growth mechanism [63, 64]. The cross sectional view of these coatings suggests fully dense coating devoid of any micro-crack or porosity.

As can be seen from the above figures, the pulsed current sample has filamentous grain morphology, and the direct current sample has a flat morphology and Nano-crystalline structure. Therefore, despite the higher hardness of the pulse sample, due to the small bandwidth in the direct current sample, and the higher coating strength by type of structure, the sample plated with direct current relative to the pulse current sample has better wear resistance behavior.
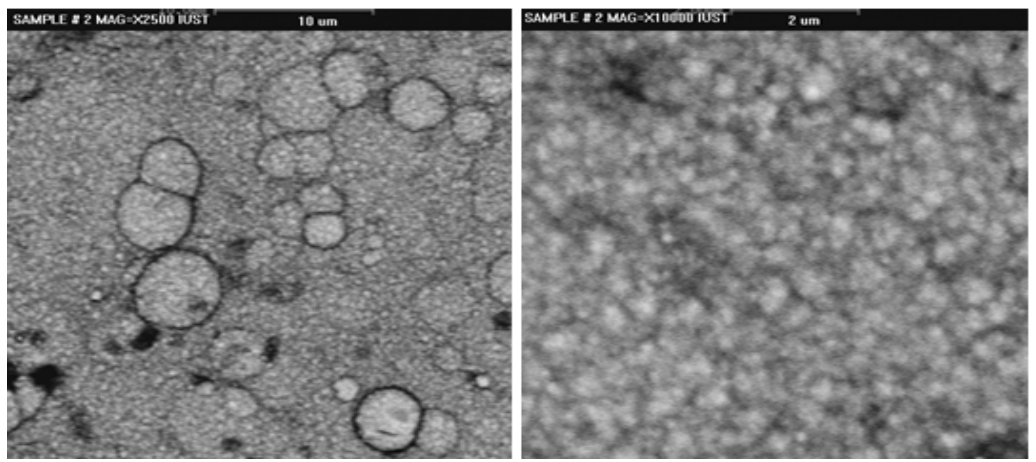

Figure 9. Morphology of sample plated by Direct current method At current density; $0.05 \mathrm{~A} / \mathrm{cm}^{2}, \mathrm{Temp}, ; 70^{\circ} \mathrm{C}, \mathrm{rpm} ; 750$.

Spherical or circular strands are quite different from the polyhedral forms of polyhedral crystals. And this is in good agreement with our expectations of amorphous alloys. The swollen spherical structure is most commonly seen in electrolytes containing ammonia, glycine, and tri- ethanolamine. The crystallized Ni-W coating decreases with increasing Tungsten content (figure 9). Tungsten atoms in supper saturated solid solution had segregated from texture to grain boundaries (dark circular lines).

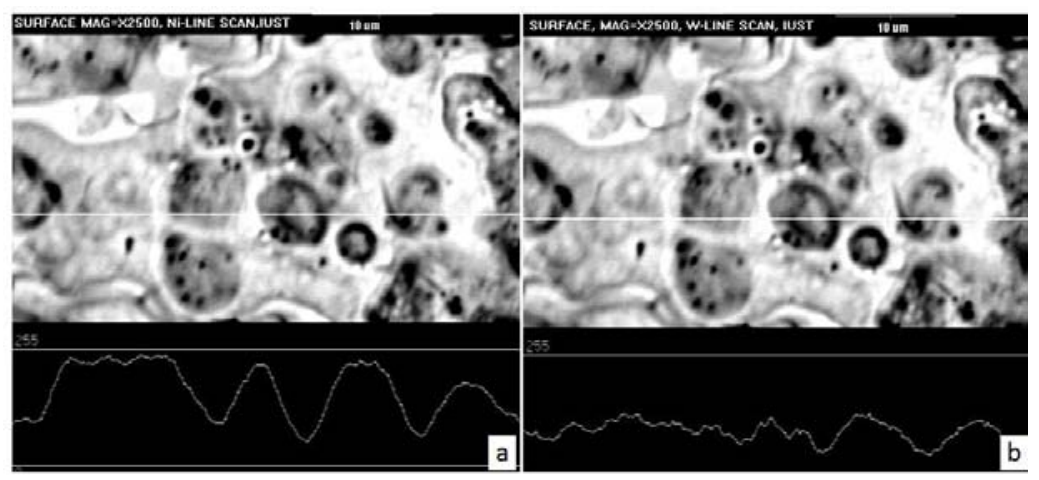

Figure 10. Morphology and line EDAX for $\mathrm{Ni}(\mathrm{a})$ and $\mathrm{W}$ (b) of sample plated by Direct current method at current density; $0.05 \mathrm{~A} / \mathrm{cm}^{2}, \mathrm{Temp}, ; 70^{\circ} \mathrm{C}, \mathrm{rpm} ; 750$, $P H=8$.

Voids across Ni-W coating surface, distributed randomly on all around the coating surface. Hydrogen had been reduced to $\mathrm{H}_{2}$ and made a hemispheric shapes on surface.
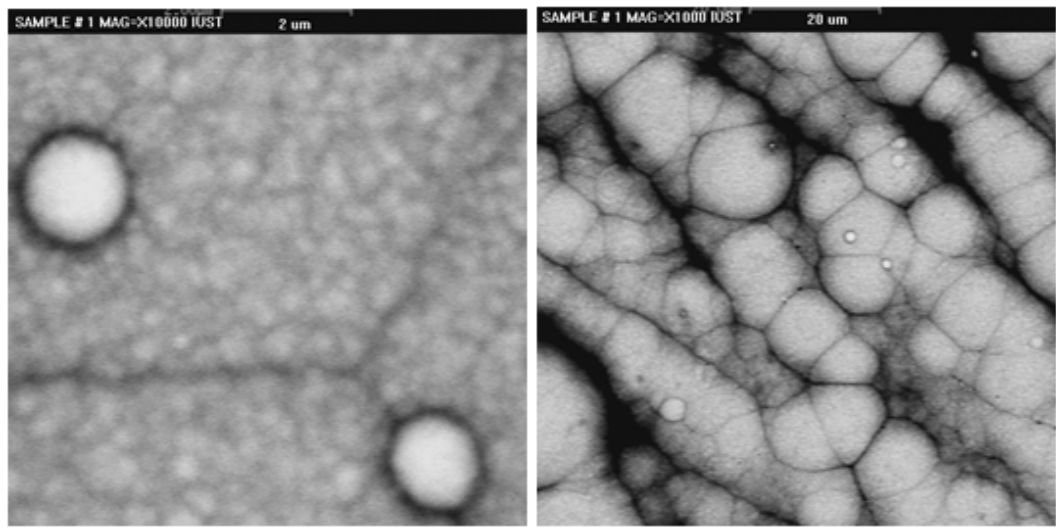

Figure 11. Morphology of sample plated by pulsed current method at \% 80 Time-on and 40Hz. Sample no. 6 in table 2. 
A nodular structure was obtained both by PED, with globular nodules of different sizes and gaps among them, indicating that they were composed of domains with different sizes. As shown in figure 11, large nodules divided intthat contained lower amount of $\mathrm{W}$, remained valume of $\mathrm{W}$ defused throw outside directs and make boundaries of new smaller grains.

Among other characteristics, PED can have an effect on the roughness of the deposits, varying from a leveling effect to an enhancement of surface microstructures and Roughness (Volmer-Weber [63, 64]) and more important, crack initiation and propagation in PED samples are meaningfully at least level in comparison to DC samples.

\section{Conclusion}

The effect of Electro-deposition parameters such as Bath's (aqueous solution of $\mathrm{NiSo}_{4}$ and $\mathrm{Na}_{2} \mathrm{Wo}_{4}$ in $\mathrm{Na}_{3} \mathrm{Cit}$ ) temperature, cathode rotation (agitation), current densities and kinds of current; Direct and Pulse parameters, in a constant electrolyte volume ratio and substrate type, had been demonstrated in this study based on the resulting morphology that characterized by SEM and EDAX.

The results of this extensive study confirm that, Anamolous is the system in Nickel-Tungsten alloy deposition in direct and pulse current plating.

$\mathrm{Ni}-\mathrm{W}$ alloy coatings were successfully electrodeposited at varies temperatures and current densities in DCED process (50, 60, $70^{\circ} \mathrm{C}$ and C.D as; $0.05,0.1,0.12 \mathrm{~A} / \mathrm{cm}^{2}$ respectively). The surface morphologies, thickness and composition of alloy coatings are greatly affected by electrodeposition temperature and current densities. The surface coarseness and $\mathrm{W}$ content in the alloy coating increases with the deposition temperature and, as shown in SEM images, By increasing current density in DC plating, coating morphology is transformed from granular to pyramidal. Meanwhile, Tungsten percentage decreased and coating grain size became coarser.

The grain size and micro hardness of the alloy coatings change with the pulse current densities in the same way as $\mathrm{Ni}-\mathrm{W}$ alloys performed in DCED. PED factors obtained the peak value of $\mathrm{W}$ as $62.8 \mathrm{wt} \%$ at the optimum temperature $70^{\circ} \mathrm{C}$ and $0.05 \mathrm{~A} / \mathrm{cm}^{2}$ and D.C of $80 \%$.

Flake like structures had been obtained by using PED technique. Coatings were found to possess superior morphology having more $\mathrm{W}$ content and hardness than that deposited by the DCED. By increasing frequencies, flakes grown and porosities had a decreasing trend in surfaces. At low Time-on percentages, coating morphology is layered, blade and porous-free. As the percentage of Time-on increases, the layers become wider.

In DCED, the morphology of the electrodeposited $\mathrm{Ni}-\mathrm{W}$ layers had cracked mud, when non-cracked continues, harder surface and more $\mathrm{W}$ wt $\%$ content in PED was investigated.

Both processes had cauliflower appearances coatings. The cauliflower growth mechanism of Ni-W alloys could be explained based the Volmer-Weber growth model.

Optimization of deposition parameters are significant towards achieving the desired morphological properties of Ni-W CCAs or HEAs coating (by definition of, content allying refractory elements, 5 and 35 atom percent). Identifying detailed multiscale analysis of characteristics of the Ni-W CCAs microstructures properties is the subject of current and future work.

\section{References}

[1] Brooman, E.; Corrosion Performance of Environmentally Acceptable Alternatives to Cadmium and Chromium Coatings: Chromium-Part II, Met. Finish. 2000, 98, 39-45.

[2] Sunwang, N.; Wangyao, P.; Boonyongmaneerat, Y. The Effects of Heat Treatments on Hardness and Wear Resistance in Ni-W Alloy Coatings, Surf. Coat. Technol. 2011, 206, 1096-1101.

[3] Haj-Taieb, M. Haseeb, A. S. M. A.; Caulfield, J.; Bade, K.; Aktaa, J.; Hemker, K. J. Thermal Stability of Electrodeposited LIGA Ni-W Alloys for High Temperature MEMS Applications. Microsyst. Technol. 2008, 14, 1531-1536.

[4] Lee, H. B.; Synergy Between Corrosion and Wear of Electrodeposited Ni-W Coating. Tribol. Lett. 2013, 50, 407-419.

[5] Udompanit, N.; Wangyao, P.; Henpraserttae, S.; Boonyongmaneerat, Y. Wear Response of CompositionModulated Multilayer Ni-W Coatings. Adv. Mater. Res. 2014, 302-309.

[6] Obradovic, M.; Stevanovic, J.; Despic, A.; Stevanoyic, R.; Stoch, J. Characterization and Corrosion Properties of Electrodeposited Ni-W Alloys. J. Serb. Chem. Soc. 2001, 66, 899-912.

[7] Younes, O. and Gileadi, E. Electrochemical and Solid State Letters, 2000, 3 (12), 543.

[8] Schuh CA, Nieh TG, Iwasaki H. Acta Mater 2003; 51: 431.

[9] Yamasaki T. Scripta Mater 2001; 44: 1497.

[10] Obradovic, M.; Stevanovic, J.; Despic, A. R. and Stevanovic, R. J. Seerb. Chec. Soc. 1999, 64 (4), 245.

[11] Fransevich_Zabludovskaya, T. F.; Zayats, A. I.;, Priklad, Zh. Khim. 1957, 30, 723.

[12] Golivenz, L. N. and Kharlamov, V. N.; Prinkl, Zh. Khim. 1936, 9, 631 .

[13] Alimadadi, H.; Ahmadi, M.; Aliofkhazraei, M.; Younesi, S. R. Corrosion Properties of Electrodeposited Nanocrystalline and Amorphous Patterned Ni-W Alloy, Mater. Des. 2009, 30, 1356-1361.

[14] Younes, O.; Shacham Diamand, Y. and Gileadi, E. In Proceedings of The Ad $\bar{d}$ vanced Metallization Conference, $\mathrm{p}$. 337, San Diego, MRS Publications, oct. 2000.

[15] Giga, A.; Kimoto, Y.; Takigawa, Y.; Higashi, K.; Demonstration of an Inverse Hall-Petch Relationship in Electrodeposited Nanocrystalline Ni-W Alloys Through Tensile Testing, Scr. Mater. 2006, 55, 143-146. 
[16] Younes, O.; Gileadi, E.; Electroplating of Ni/W Alloys I. Ammoniacal Citrate Baths, J. Electrochem. Soc. 2002, 149, C100-C111.

[17] Zhao, C.; Yao, Y.; He, L.; Electrodeposition and Characterization of $\mathrm{Ni}-\mathrm{W} / \mathrm{ZrO}_{2}$ Nanocomposite Coatings. Bull. Mater. Sci. 2014, 37, 1053-1058.

[18] Beltowska-Lehman, E.; Indyka, P.; Bigos, A.; Szczerba, M.; Guspiel, J.; Koscielny, H.; Kot, M. Effect of Current Density on Properties of Ni-W Nanocomposite Coatings Reinforced with Zirconia Particles. Mater. Chem. Phys. 2016, DOI.

[19] Kumar, K. A.; Kalaignan, G. P.; Muralidharan, V.; Direct and Pulse Current Electrodeposition of Ni-W-TiO Nanocomposite Coatings. Ceram. Int. 2013, 39, 2827-2834.

[20] Yamasaki, T.; Schlo $\beta$ macher, P.; Ehrlich, K.; Ogino, Y.; Formation of Amorphous Electrodeposited Ni-W Alloys and Their Nanocrystallization. Nanostruct. Mater. 1998, 10, 375388 .

[21] Wasekar, N. P.; Sundararajan, G. Sliding Wear Behavior of Electrodeposited Ni-W Alloy and Hard Chrome Coatings. Wear 2015, 342-343, 340-348.

[22] W. Martienssen, H. Warlimont, Springer Handbook of Condensed Matter and Materials Data, Springer, Heidelberg, New York, 2005.

[23] J. G. Fleming, S. S. Mani, J. J. Sniegowski, R. S. Blewer, Tungsten coating for improved wear resistance and reliability of microelectromechanical devices, United States Patent No. 62908592001 .

[24] S. M. Rossnagel, I. C. Noyan, C. Cabral, Phase transformation of thin sputter-deposited tungsten films at room temperature, J. Vac. Sci. Technol. B: Nanotechnol. Microelectron.: Mater. Process. Meas. Phenom. 20 (2002) 2047.

[25] T. Z. Hossain, A. R. Ghatak-roy, A. Evans, Tungsten interconnect method, United States Patent No. 62744722001.

[26] M. Itoh, M. Hori, S. Nadahara, The origin of stress in sputterdeposited tungsten films for X-ray masks, J. Vac. Sci. Technol. B: Nanotechnol. Microelectron.: Mater. Process. Meas. Phenom. 9 (1991) 149.

[27] I. A. Weerasekera, S. I. Shah, D. V. Baxter, K. M. Unruh, Structure and stability of sputter deposited beta-tungsten thin films, Appl. Phys. Lett. 64 (1994) 3231.

[28] I. Djerdj, A. M. Tonejc, A. Tonejc, N. Radic, XRD line profile analysis of tungsten thin films, Vacuum 80 (2005) 151.

[29] N. Radić, A. Tonejc, J. Ivkov, P. Dubček, S. Bernstorff, Z. Medunić, Sputter-deposited amorphous-like tungsten, Surf. Coat. Technol. 180-181 (2004) 66.

[30] Detor AJ, Schuh CA. Acta Mater 2007; 55: 371.

[31] Slavcheva E, Mokwa W, Schnakenberg U. Electrodeposition and properties of NiW films for MEMS application. Electrochim Acta 2005; 50: 5573-80.

[32] Fritz T, Mokwa W, Schnakenberg U. Electrodeposited nickeltungsten alloys for micro-engineering-part 2: deposition from a sulphamate electrolyte. Galvanotech 2002; 92: 2684-90.

[33] Wu Y, Chang D, Kim D, Kwon S. Influence of boric acid on the electrodepositing process and structures of $\mathrm{Ni}-\mathrm{W}$ alloy coating. Surf Coat Technol 2003; 173: 259-64.
[34] Yao S, Zhao S, Guo H, Kowaka M. A new amorphous alloy deposit with high corrosion resistance. Corrosion 1996; 52: $183-6$.

[35] Valiev RZ, Islamgaliev RK, Alexandrov IV. Bulk nanostructured materials from severe plastic deformation. Prog Mater Sci 2000; 45: 103-89.

[36] A. D. Maksic, S. M. Miulovic, V. M. Nikolic, I. M. Perovic, M. P. M. Kaninski, Energy consumption of the electrolytic hydrogen production using Ni-W based activators-Part I, Applied Catalysis A: General, 405 (2011) 25-28.

[37] S. H. Hong, S. H. Ahn, J. Choi, J. Y. Kim, H. Y. Kim, H. J. Kim, J. H. Jang, H. Kim, S. K. Kim, High-Activity Electrodeposited NiW Catalysts for Hydrogen Evolution in Alkaline Water Electrolysis, Appl. Surf. Sci., DOI (2015).

[38] C. N. Panagopoulos, G. D. Plainakis, M. G. Tsoutsouva, Corrosion of Nanocrystalline Ni-W Coated Copper, Journal of Surface Engineered Materials and Advanced Technology, 5 (2015) 65.

[39] I. Mizushima, P. T. Tang, M. A. J. Somers, Identification of an anomalous phase in Ni-W electrodeposits, Surf. Coat. Technol., 202 (2008) 3341-3345.

[40] R. Juškènas, I. Valsiūnas, V. Pakštas, A. Selskis, V. Jasulaitienè, V. Karpavičienè, V. Kapočius, XRD, XPS and AFM studies of the unknown phase formed on the surface during electrodeposition of Ni-W alloy, Appl. Surf. Sci., 253 (2006) 1435-1442.

[41] T. Sridhar, N. Eliaz, E. Gileadi, Electroplating of Ni4 W, Electrochem. Solid-State Lett., 8 (2005) C58-C61.

[42] A. Królikowski, E. Płońska, A. Ostrowski, M. Donten, Z. Stojek, Effects of compositional and structural features on corrosion behavior of nickel-tungsten alloys, J Solid State Electrochem, 13 (2009) 263-275.

[43] T. Yamasaki, High-strength nanocrystalline Ni-W alloys produced by electrodeposition, Materials Physics and Mechanics (Russia), 1 (2000) 127-132.

[44] L. Zhu, O. Younes, N. Ashkenasy, Y. Shacham-Diamand, E. Gileadi, STM/AFM studies of the evolution of morphology of electroplated Ni/W alloys, Appl. Surf. Sci., 200 (2002) 1-14.

[45] A. Chianpairot, G. Lothongkum, C. A. Schuh, Y. Boonyongmaneerat, Corrosion of nanocrystalline Ni-W alloys in alkaline and acidic $3.5 \mathrm{wt} . \% \mathrm{NaCl}$ solutions, Corros. Sci., 53 (2011) 1066-1071.

[46] P. Indyka, E. Beltowska-Lehman, L. Tarkowski, A. Bigos, E. García-Lecina, Structure characterization of nanocrystalline $\mathrm{Ni}-\mathrm{W}$ alloys obtained by electrodeposition, J. Alloys Compd., 590 (2014) 75-79.

[47] T. Nasu, M. Sakurai, T. Kamiyama, T. Usuki, O. Uemura, T. Yamasaki, EXAFS study on amorphous and nanocrystalline $\mathrm{M}-\mathrm{W}(\mathrm{M}=\mathrm{Fe}, \mathrm{Ni})$ alloys produced by electrodeposition, $\mathrm{J}$. Non-Cryst. Solids, 312 (2002) 319-322.

[48] S. Hayata, S. Oue, H. Nakano, T. Takahashi, Effect of Annealing on the Structure and Hardness of Electrodeposited Ni-W Alloys, ISIJ Int., 55 (2015) 1083-1090. 
[49] N. S. Nia, J. Creus, X. Feaugas, C. Savall, Influence of metallurgical parameters on the electrochemical behavior of electrodeposited $\mathrm{Ni}$ and Ni-W nanocrystalline alloys, Appl. Surf. Sci., 370 (2016) 149-159.

[50] R. Juškènas, I. Valsiūnas, V. Pakštas, R. Giraitis, On the state of $\mathrm{W}$ in electrodeposited Ni-W alloys, Electrochim. Acta, 54 (2009) 2616-2620.

[51] M. H. Allahyarzadeh, M. Aliofkhazraei, A. R. Rezvanian, V. Torabinejad, A. R. S. Rouhaghdam, Ni-W electrodeposited coatings: Characterization, properties and applications, Surf. Coat. Technol. 307 (2016) 978-1010.

[52] P. Indyka, E. Beltowska-Lehman, A. Bigos, Microstructural characterisation of electrodeposited coatings of metal matrix composite with alumina nanoparticles, IOP C Ser. Mater. Sci. Eng. 32 (2012).

[53] L. Ribic-Zelenovic, N. Cirovic, M. Spasojevic, N. Mitrovic, A. Maricic, V. Pavlovic, Mater. Chem. Phys. 135 (2012) 212.

[54] A. S. M. A. Haseeb, U. Albers, K. Bade, Wear 264 (2008) 106-112.

[55] L. M. Chang, Z. T. Wang, S. Y. Shi, W. Liu, Study on microstructure and properties of electrodeposited Ni-W alloy coating with glycolic acid system, J. Alloys Compd., 509 (2011) 1501-1504.
[56] M. Donten, H. Cesiulis, Z. Stojek, Electrochim. Acta 45 (2000) 3389 .

[57] R. A. C. Santana, S. Prasad, A. R. N. Campos, F. O. Arajo, G. P. da Silva, P. de Lima-Neto, J. Appl. Electrochem. 36 (2006) 105.

[58] H. E. Feng-jiao, Miao. Wang, L. U. Xin, Trans. Nonferr. Met. Soc. China 16 (2006) 289.

[59] H. Somekawa, T. G. Neigh, K. Higashi, Scripta Mater. 50 (2004) 1361.

[60] K. R. Sriraman, S. Ganesh Sundara Raman, S. K. Seshadr, Mater. Sci. Eng. A 418-303 (2006) 31.

[61] R. L. Fleischer, Substitutional solution hardening, Acta Metallurgica 11 (3) (1963) 203-209.

[62] R. Labusch, A statistical theory of solid solution hardening, physica status solidi (b) 41 (2) (1970) 659-669.

[63] K. A. Lozovoy, A. P. Kokhanenko, Vladimir V. Dirko, Yu. Akimenko, and Alexander V. Voitsekhovskii, Cryst. Growth Des, DOI: 10.1021/acs.cgd.9b00820.

[64] V. Elofsson, B. Lü, D. Magnfält, E. P. Münger, and K. Sarakinos, Journal of Applied Physics 116, 044302 (2014); doi: $10.1063 / 1.4890522$. 